\title{
TWO DIPOLE MAGNETIC SYSTEMS FOR TECHNOLOGICAL ELECTRON ACCELERATOR
}

\author{
V.A. Bovda, A.M. Bovda, I.S. Guk, A.N. Dovbnya, S.G. Kononenko, V.N. Lyashchenko, \\ A.O. Mytsykov, L.V. Onishchenko \\ National Science Center “Kharkov Institute of Physics and Technology”, Kharkiv, Ukraine \\ E-mail: guk@kipt.kharkov.ua
}

For a $10 \mathrm{MeV}$ technological accelerator, a dipole magnet with a permanent magnetic field was created using the SmCo alloy. The maximum magnetic field in the magnet gap was $0.3 \mathrm{~T}$. The magnet is designed to measure the energy of the beam and to adjust the accelerator for a given energy. For a linear accelerator with an energy of $23 \mathrm{MeV}$, a dipole magnet based on the Nd-Fe-B alloy was developed and fabricated. It was designed to rotate the electron beam at a 90 degrees. The magnetic field in the dipole magnet along the path of the beam was $0.5 \mathrm{~T}$. The effective length of the magnet was $242 \mathrm{~mm}$.

PACS: $29.30 . \mathrm{Kv}$

\section{INTRODUCTION}

High performance rare-earth permanent magnets allow various designs of dipole magnetic systems for medical and technological accelerators, microtrones and linear colliders [1 - 5]. Despite the well-known basic principals of magnetic system layout, every magnetic system is made almost adhoc due to the particularparameters of the accelerator and operation conditions. In this paper, we present magnetic systems (dipole magnets) on the base of Nd-Fe-B and Sm-Co magnets. Dipole magnets on the base of Nd-Fe-B and Sm-Co permanent magnets are used in two upgraded electron accelerators in NSC KIPT.

\section{MAGNETIC SYSTEM (DIPOLE MAGNET) FOR THE LU-10 ELECTRON ACCELERATOR WITH THE ENERGY OF $10 \mathrm{MeV}$}

LU-10 is an electron accelerator used for the radiation treatment of materials and devices in the energy range of $10 \mathrm{MeV}$ [6]. An upgrade of the LU-10 accelerator will raise the beam power to $20 \mathrm{~kW}$. The important task of the upgrade is to measure beam energy at the peak output.

It is known that high performance permanent magnets can be used for the designing compact devices detecting electron beam parameters $[2,5]$. Thus, simple, cost-effective and free of power source device on the base of powerful permanent magnets can be created. This device is suitable for analyzing beam parameters at the energies up to $10 \mathrm{MeV}$.

In order to choose appropriate magnetic material for detecting device, the radiation resistance of $\mathrm{Sm}-\mathrm{Co}$ and Nd-Fe-B magnets was studied [7, 8]. Magnetic samples underwent direct electron beam treatment with the energy of $10 \mathrm{MeV}$ and bremsstrahlung. Absorbed dose for electrons was 16 and $160 \mathrm{Grad}$. The temperature of magnets under irradiation was about $38^{\circ} \mathrm{C}$. Whereas magnetic flux of $\mathrm{Nd}-\mathrm{Fe}-\mathrm{B}$ magnets decreased in 0.92 and 0.717 times for 16 Grad and 160 Grad accordingly, magnetic performance of $\mathrm{Sm}-\mathrm{Co}$ magnets remained unchanged under the same radiation doses. Radiation activity of both Nd-Fe-B and Sm-Co magnets after irradiation was not increased above critical levels. It makes the Nd-Fe-B and Sm-Co permanent magnets more ap- propriate for accelerator's applications. The additional advantage of Sm-Co magnets is low temperature coefficient of remanence $0.035\left(\% /{ }^{\circ} \mathrm{C}\right)$.

To assess the parameters of dipole magnet, the simulation of beam travel at the output of the accelerator was carried out [9].

The parameters of the beam and magnetic field inside dipole magnet were fixed. The typical size of SmCo magnets for the design of dipole magnets was $30 \times 24 \times 12 \mathrm{~mm}$. The distance between Sm-Co magnets was $25 \mathrm{~mm}$. The typical magnetic field in the mid-plane of the dipole magnet was about $0.3 \mathrm{~T}$. This peak magnetic field of $0.3 \mathrm{~T}$ was used for the simulation of beam travel.

Hence, the simulation allowed building the construction of dipole magnet (Fig. 1).

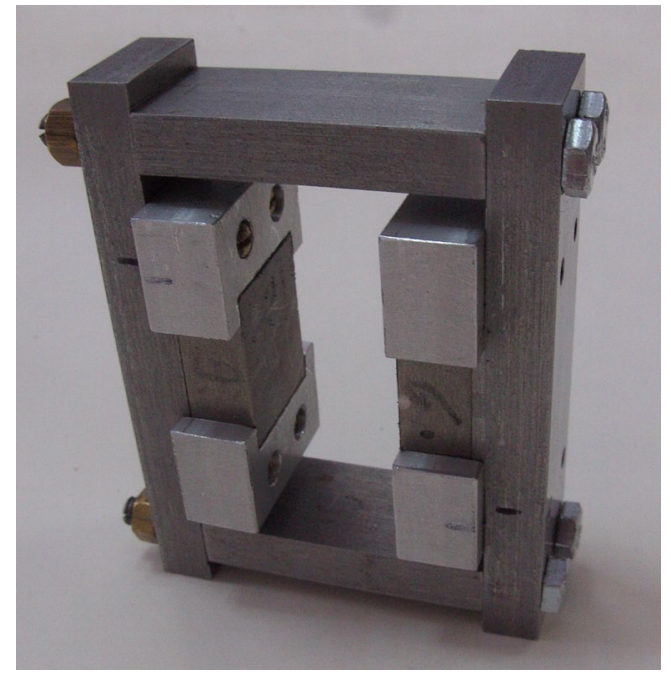

Fig. 1. Dipole magnet (assembled) for the LU-10

electron accelerator with the energy of $10 \mathrm{MeV}$

This layout yields easy beam rotation in the both vertical and horizontal directions.

Outside dimensions of the magnetic circuit were $90 \times 73 \times 24 \mathrm{~mm}$. The magnetic circuit was made of soft magnetic steel. The tolerance and machining of parts were 5 microns. The upper bar was designed portable to facilitate the dismantling of the dipole magnet and the flange of accelerator during the measuring mode or adjustment accelerator energy procedure.

The mid-plane scans in the gap of dipole magnet are shown in Fig. 2. 


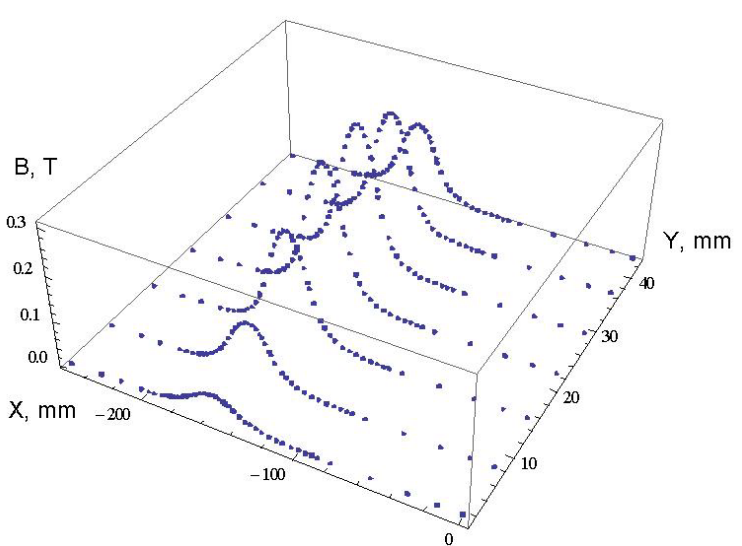

Fig. 2. Magnetic field distribution in the dipole magnet

The measurements details can be found elsewhere [7].

The distributions of the magnet field, obtained as a result of interpolation of the experimental data, are presented in Fig. 3. This distribution of the magnet field is close to the field distribution obtained as a result of a preliminary selection of the parameters of the magnet and simulation of the field distribution in it [9].

It was revealed that peak magnetic field in the gap of dipole magnet was $0.331103 \mathrm{~T}$. The effective length along the central line of beam track was $-33.533 \mathrm{~mm}$. The rotation angle of electron beam with the energy of $10 \mathrm{MeV}$ was $0.31 \mathrm{rad}$. The estimation of the rotation angle was done according to the simulation of electron beam motion.

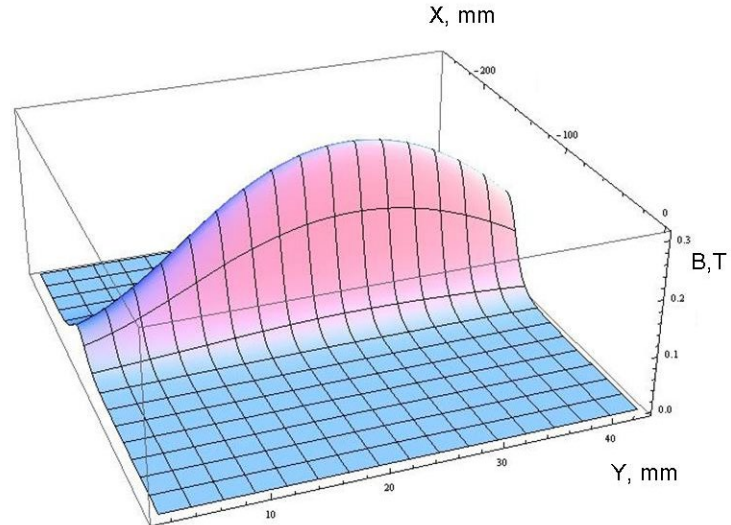

Fig. 3. Magnetic field distribution in the mid-plane of gap of dipole magnet for the LU-10 electron accelerator with the energy of $10 \mathrm{MeV}$

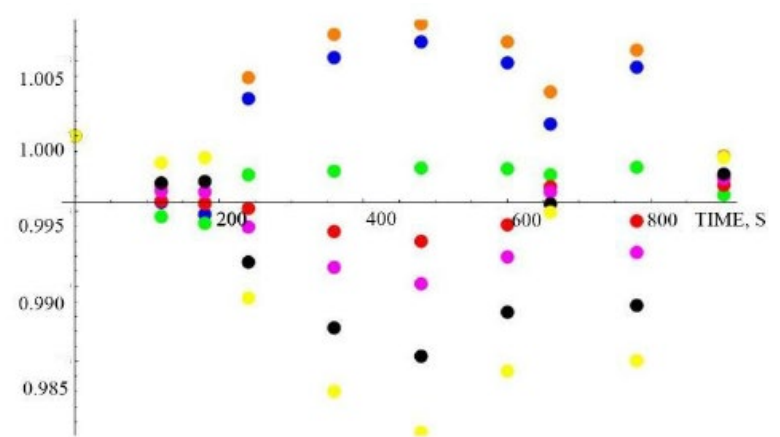

Fig. 4. The change of magnetic field (Hall probe data) after each cycle

The deviation of magnetic field in the gap of dipole magnet was investigated under various regimes as opening and closing circuit, and the reconfiguration of the upper bar. Fig. 4 shows the measurements of seven Hall probes in the gap of dipole magnet during 10 cycles of opening and closing circuit for 1000 seconds [7]. Points of the one color depict the change of magnetic field at the point of each Hall probe after each cycle.

The variation of data of Hall probe located in the centre of the gap (green, red and pink points) was not more than $0.5 \%$ after closing circuit.

\section{MAGNETIC SYSTEM (DIPOLE MAGNET) FOR "EPOS" TECHNOLOGICAL ACCELERATOR}

"EPOS" linear electron accelerator is used for the radiation treatment of materials and products [6]. The upgrade of the "EPOS" resulted in the redesign of output unit with the addition of the second channel. Dipole magnet was provided for the rotation of the electron beam with the energy of $23 \mathrm{MeV}$ at a 90 degree. In order to locate the rotary part of beam channel on the accelerator frame, a maximum magnetic field of $0.516 \mathrm{~T}$ in the magnet gap of $25 \mathrm{~mm}$ width was required. Given the existing energy fluctuation of electron beam, the dipole magnet yoke should be $50 \mathrm{~mm}$ long including shims and $1 \mathrm{~mm}$ in height at the edges to guarantee the radius uniformity.

Unfortunately, the existing electron beam forming and transporting system of the "EPOS" accelerator is not able to eliminate the loss of electrons at the walls of the vacuum chamber of dipole magnet. It was shown that direct irradiation of $\mathrm{Nd}-\mathrm{Fe}-\mathrm{B}$ magnets by the $23 \mathrm{MeV}$ electrons with absorbed doses of 16 and $160 \mathrm{Grad}$ let to the decrease of magnetic properties [10]. However, the bremsstrahlung of the $23 \mathrm{MeV}$ electron's beam was not affected the magnetic performance of $\mathrm{Nd}$ Fe-B magnets. Thus, the location of dipole magnet was designed as far away as possible from the electron beam to discard the direct interaction of $\mathrm{Nd}-\mathrm{Fe}-\mathrm{B}$ magnets with electrons. Upgraded device is shown in Fig. 5.

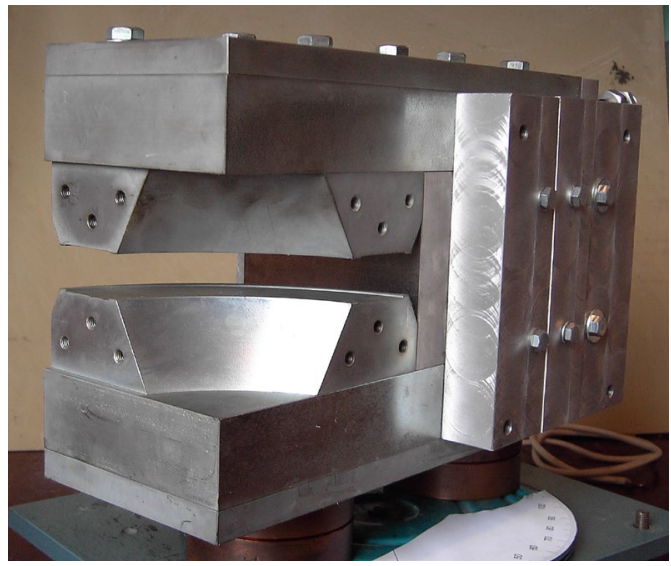

Fig. 5. Dipole magnet for "EPOS” linear electron accelerator (face)

The magnetic field in the gap was formed by the magnetic yoke and pole pieces made of low-carbon steel. The upper and lower parts of the dipole magnet were composed of two pieces. Special $\mathrm{Cu}$-tube was installed in the beam channel and attached to the accelerator thermoregulation system (Fig. 6).

The effective length of the dipole magnet can be altered by fasting small segments with the cross-section 
similar to pole tips. The stability of the gap size was provided by the titanium insert, behind which there was a box for Nd-Fe-B magnets assembly. The position of the blocks is fixed using a system of bolts in the walls of the box. The box is made of aluminum alloy.

The geometry tolerance of the dipole magnet components was about 5 microns.

Due to technological requirements, the magnetic unit of the required size was composed of magnetized $\mathrm{Nd}$ $\mathrm{Fe}-\mathrm{B}$ magnets. Nd-Fe-B magnets of rectangular shape with the size of $50 \times 50 \times 10 \mathrm{~mm}$ were used. Overall dimensions of the dipole magnet are $233 \times 170 \times 435 \mathrm{~mm}$.

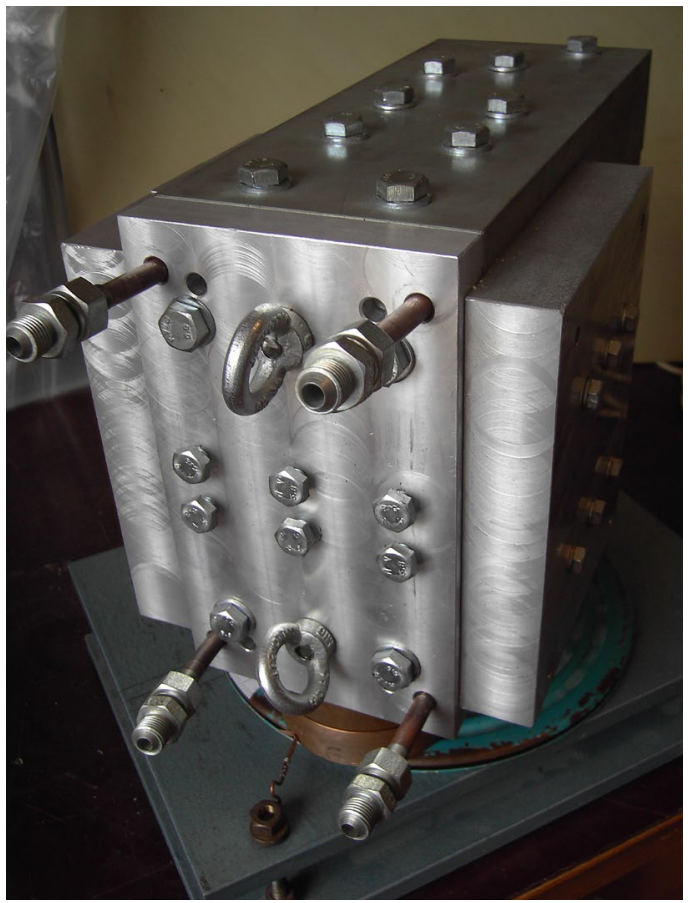

Fig. 6. Dipole magnet for "EPOS" linear electron accelerator (back view)

The distribution of magnetic field of the dipole magnet along the beam path is depicted in Fig. 7 accordingly. Measurements details can be seen in elsewhere [5].

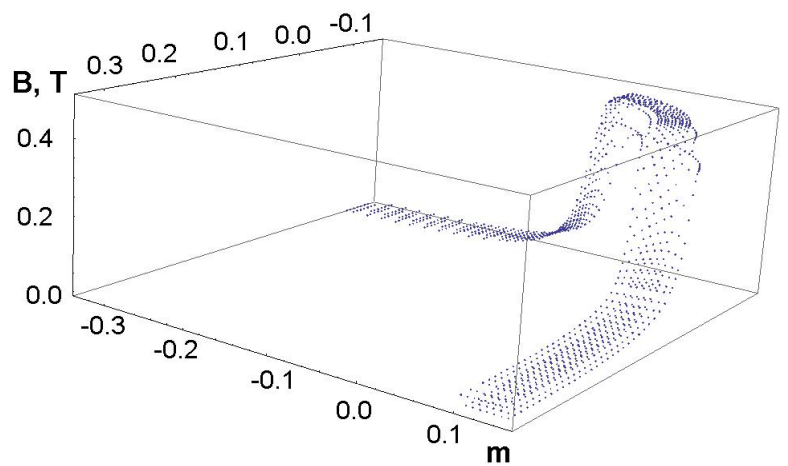

Fig. 7. Magnetic field of the dipole magnet along the beam path ("EPOS" linear electron accelerator)

The distribution of normal component of magnetic field to the beam path is seen in Fig. 8.

The effective length of the dipole magnet was $242 \pm 1.1 \mathrm{~mm}$. It was calculated using the trace of the particle with the energy of $23 \mathrm{MeV}$.

Beam tracing using experimental magnetic field measurements was carried out. The beam trajectory with ISSN 1562-6016. BAHT. 2019. №6(124) experimental parameters passed through dipole magnet within specified limits.

B, T

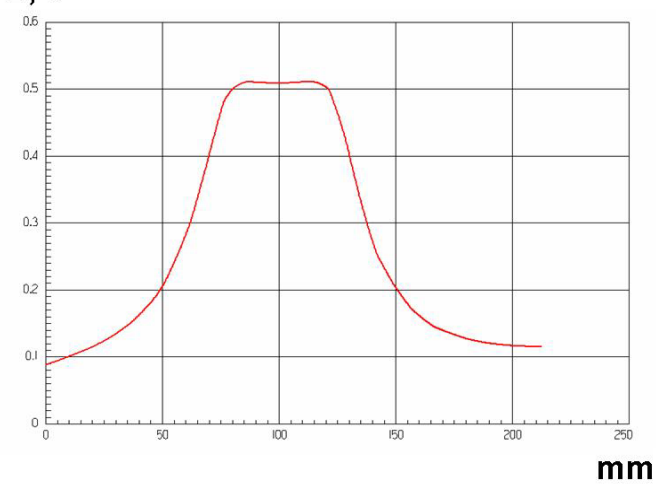

Fig. 8. Central-pole magnetic field distribution transverse to the beam path ("EPOS" linear electron accelerator)

It is well known that magnetic performance of $\mathrm{Nd}$ Fe-B magnets critically depends on temperature. The ambient temperature of accelerator unit varies widely. Such temperature deviations could influence the beam position at the exit of magnetic system. Fig. 9 shows the temperature dependence of the magnetic field in the dipole magnet. The temperature range covers all real thermal conditions of the accelerator unit.

When developing the dipole magnet, it was supposed to use the accelerator temperature control unit to keep the ambient conditions. Water temperature in the accelerator temperature control unit is about $38^{\circ} \mathrm{C}$.

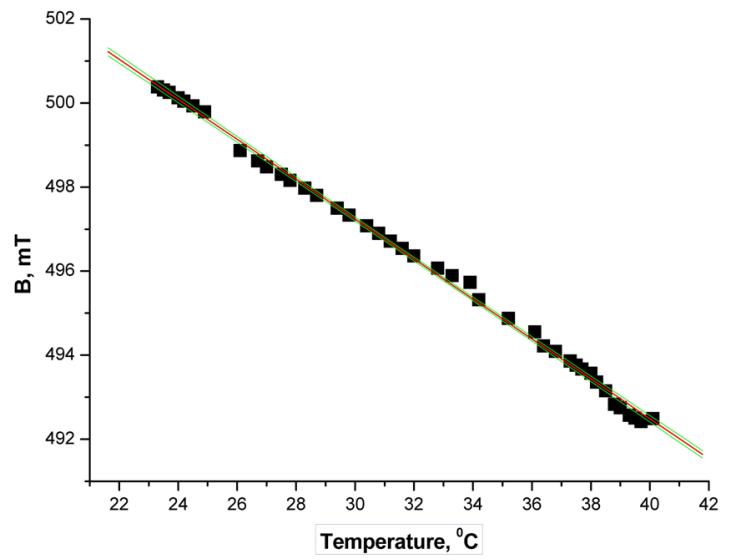

Fig. 9. Temperature dependence of the magnetic field in the dipole magnet ("EPOS" linear electron accelerator)

\section{SUMMARY}

In summary, two types of dipole magnets were designed and produced for the technological electron accelerators (10 and $23 \mathrm{MeV})$. The key component of dipole magnets is rare-earth permanent magnets with high magnetic properties. Proposed and verified design of the dipole magnets enables their use under high radiation conditions.

\section{REFERENCES}

1. V.I. Svedunov et al. A $70 \mathrm{MeV}$ Race-Track Microtron // Nucl. Instr. Meth. 2005, v. 550, № 1-2, p. 39-53.

2. J. David et al. Permanent-magnet energy spectrometer for electron beams from radiotherapy accelerators // Medical Physics, 2015, v. 42, p. 5517. 
3. F. Bødker. Permanent magnets in accelerators can save energy, space and cost // Proc. of IPAC2013, Shanghai, China, p. 3511-3513.

4. A. Bainbridge, B. Shepherd, N. Collomb, J. Clarke, M. Modena. The ZEPTO project: Tuneable permanent magnets for the next generation of high energy accelerators // Proc. 25-th International Conference on Magnet Technology, Amsterdam, 30-th August 2017, TalkID\#448, session Wed-Mo-Or19.

5. A.M. Bovda, I.S. Guk, A.N. Dovbnya, S.G. Kononenko, V.N. Lyashchenko, A.O. Mytsykov. Dipole magnet with a constant field for the accelerator "EPOS" // Problems of Atomic Science and Technology. Series "Nuclear Physics Investigations”. 2015, № 6, p. 13-17.

6. M.I. Ayzatsky et al. The NSC KIPT electron linacs - R\&D // Problems of Atomic Science and Technology. Series "Nuclear Physics Investigations". 2003, № 2, p. 19-25.
7. A.M. Bovda et al. Magnetic properties of $\mathrm{Sm}_{2} \mathrm{Co}_{17}$ magnets under $10 \mathrm{MeV}$ electron beam // Problems of Atomic Science and Technology. Series "Nuclear Physics Investigations”. 2017, № 6, p. 162-166.

8. V.A. Bovda et al. Magnetic field losses in Nd-Fe-B magnets under $10 \mathrm{MeV}$ electron irradiation // Problems of Atomic Science and Technology. Series "Nuclear Physics Investigations”. 2017, № 3, p. 90-94.

9. I.S. Guk, S.G. Kononenko, V.N. Lyashchenko, A.O. Mytsykov. Choice of parameters of the analyzing magnet for technological electron accelerator LU-10M // Problems of Atomic Science and Technology. Series “Nuclear Physics Investigations”. 2017, № 6, p. 24-27.

10. V.A. Bovda et al. Magnetic properties of Nd-Fe-B magnets under electron beam irradiation with the energy $23 \mathrm{MeV} / /$ Problems of Atomic Science and Technology. Series "Nuclear Physics Investigations”. 2018, № 3, p. 163-167.

Article received 01.04.2019

\section{ДВА ДИПОЛЬНЫХ МАГНИТА ДЛЯ ТЕХНОЛОГИЧЕСКИХ УСКОРИТЕЛЕЙ ЭЛЕКТРОНОВ \\ В.А. Бовда, А.М. Бовда, И.С. Гук, А.Н. Довбня, С.Г. Кононенко, В.Н. Ляценко, А.О. Мыцыков, Л.В. Онищенко}

Для технологического ускорителя на энергию 10 МэВ создан дипольный магнит с постоянным полем с использованием SmCo-сплава. Максимальное поле в магните равно 0,3 Тл. Магнит предназначен для измерения энергии пучка и для настройки ускорителя на заданную энергию. Для линейного ускорителя с энергией 23 МэВ разработан и изготовлен дипольный магнит на основе $\mathrm{Nd}-\mathrm{Fe}-\mathrm{B}-$ сплава. Он предназначен для поворота пучка электронов на 90 градусов. Поле в магните вдоль траектории движения пучка равно 0,5 Тл. Эффективная длина магнита равна 242 мм.

\section{ДВА ДИПОЛЬНИХ МАГНІТИ ДЛЯ ТЕХНОЛОГІЧНИХ ПРИСКОРЮВАЧІВ ЕЛЕКТРОНІВ В.О. Бовда, О.М. Бовда, І.С. Гук, А.М. Довбня, С.Г. Кононенко, В.М. Лященко, А.О. Мициков, Л.В. Оніщенко}

Для технологічного прискорювача на енергію 10 МеВ створено дипольний магніт з постійним полем 3 використанням SmCo-сплаву. Максимальне поле в магніті дорівнює 0,3 Тл. Магніт призначений для визначення енергії пучка і настроювання прискорювача на задану енергію. Для лінійного прискорювача 3 енергією $23 \mathrm{MeB}$ розроблений і виготовлений дипольний магніт на основі Nd-Fe-B-сплаву. Він призначений для повороту пучка електронів на 90 градусів. Поле в магніті уздовж траєкторії руху пучка дорівнює 0,5 Тл. Ефективна довжина магніту дорівнює 242 мм. 